Available online at GSC Online Press Directory

GSC Biological and Pharmaceutical Sciences

e-ISSN: 2581-3250, CODEN (USA): GBPSC2

Journal homepage: https://www.gsconlinepress.com/journals/gscbps

(RESEARCH ARTICLE)

\title{
Pharmaceutical equivalence and similarity studies of glibenclamide tablets
}

\author{
Sánchez-Nava Luis Alberto, Bautista-Sánchez Urias and Robles-Piedras Ana Luisa* \\ Academic Area of Pharmacy. Institute of Health Sciences, Autonomous University of the State of Hidalgo. Ex-Hacienda La \\ Concepción Circuit, Km. 1.5, San Agustín Tlaxiaca, Hidalgo. c.p. 42160, Mexico.
}

Publication history: Received on 28 March 2019; revised on 16 April 2019; accepted on 22 April 2019

Article DOI: https://doi.org/10.30574/gscbps.2019.7.1.0053

\begin{abstract}
The in vitro dissolution is the physicochemical test most used to estimate the release of the drug from the pharmaceutical form. Due to the close relationship between the dissolution rate of the drug in vitro and the absorption in vivo, the dissolution study is considered as the necessary and sufficient criterion to allow the commercialization of a pharmaceutical product. In this study, the similarity of the dissolution profiles of different products containing glibenclamide used in the Mexican Health Sector was compared. The dissolution profiles of 7 generic products were constructed and analyzed and compared with the innovative drug. The quality control carried out showed that one generic product did not comply with the specifications. Two products showed no difference in the percentage dissolved compared to the reference product; however, none of the products presented a parallel behavior to the innovator. Only one of the seven pharmaceutical products used in the Health Sector met the interchangeability criteria. Properly controlled bio-equivalence studies are strongly recommended to further investigate the potential inequivalence of the tested products.
\end{abstract}

Keywords: Glibenclamide; Dissolution; Pharmaceutical equivalence

\section{Introduction}

Each pharmaceutical formulation of a drug is unique in its biopharmaceutical behavior, so it can potentially be an important determinant factor of the efficacy and safety of the clinical response. Most of the pharmaceutical preparations that are currently being used are composed of solid dosage forms and constitute the pharmaceutical form more used, which represents between 40 and $70 \%$ of the total production of the pharmaceutical forms commercially available. In these pharmaceutical forms, the amount of drug that reaches the site of action depends on the release of this from the pharmaceutical form. In this sense, some authors have reported the existence of differences in the release of the drug between batch and batch of the same medicinal product, and have shown that this release depends directly on both chemical and technological factors $[1,2]$.

One of the tests that determine the differences in the manufacturing process from batch to batch, is the study of the dissolution behavior of the solid dosage forms, which is also a useful parameter to demonstrate the interchangeability of medications that contain the same drug at the same dosage and the same pharmaceutical form.

There are various studies in which is demonstrated the existence of differences in the bioavailability and bioequivalence in formulations of different therapeutic groups. Particularly in the case of formulations containing glibenclamide in single dose, differences were found in terms of the rate of absorption between drug products that have been manufactured by different pharmaceutical companies $[1,3,4]$.

\footnotetext{
${ }^{*}$ Corresponding author

E-mail address: roblesa@uaeh.edu.mx
} 
The differences in the bioavailability differ between 80 to $100 \%$; there is also evidence of a reduction of $40 \%$ in the bioavailability of glibenclamide when it is administered in a non-micronized form [5,6]. The incidence of these problems lies in the fact that there are clear differences in their dissolution profile and the lack of effect [7].

Likewise, in Mexico it has been shown that some pharmaceutical products containing glibenclamide available in pharmacies do not comply with the quality control parameters, which could result in low concentrations and the possibility of a lack of glycemic control in the patients. At the Mexican Institute of Social Security (IMSS), glibenclamide belongs to the basic list of essential drugs, and constitutes one of the first-choice drugs along with metformin for the treatment of diabetes mellitus. In Mexico, for several decades it has been shown that there are problems with the supply of medicines, an analysis conducted by the Mexican Ministry of Health, showed that only $26 \%$ of the medical units of first level of attention had metformin. At the same time, there is a prevalence of $7 \%$ diabetes in the population from 20 to 69 years, and constitutes the second cause of death; this fact is reflected at the IMSS, where diabetes mellitus is one of the first three causes of death. In Mexico, in 2016, this disease represented 14\% of the total recorded deaths and the expenses derived from the care of diabetic patients, exceed the 200 million dollars annually [8].

In the different institutions that are part of the Health Sector in Mexico, there is a wide variability in the acquisition of the drugs that are dispensed in pharmacies of this sector, and this is due to the fact that there are several laboratories that participate in the biddings for the purchase of medicines. As a result of this, patients receiving chronic therapies, such as in the case of the treatment of type 2 diabetes mellitus, are exposed to the provision of the same drug, in the same pharmaceutical form, but developed by different laboratories.

The exchange or replacement of a medicinal product should not be governed exclusively by the criteria of simplicity in its manipulation or reduction of economic cost, should also be considered the concepts of bioavailability and bioequivalence to be able to say that two drugs are substitutable.

\section{Material and methods}

Analytical grade hydrochloric acid, sodium hydroxide, sodium borate, potassium chloride and glibenclamide reference substance were purchased from Sigma-Aldrich (San Louis Missouri, USA). For the preparation of solutions, deionized water obtained in a Millipore $®$ system was used.

Eight solid tablets dosage formulations containing $5 \mathrm{mg}$ of drug were studied: Daonil®) (Sanofi-Aventis, Mexico) as innovator (product A) versus seven formulations of various suppliers of the Mexican health sector (product B, C, D, E, F, $\mathrm{G}$ and $\mathrm{H}$ ). The innovator product was purchased at a pharmacy, and the other products were donated by the IMSS.

\subsection{Instrumentation and chromatographic conditions}

An Agilent 1100 series HPLC (Wilmington, DE, USA) consisted of a quaternary pump, an automatic injector, variable wavelength detector, and a column oven. Data was collected using Agilent ChemStation software.

LC separation was carried out using a Keystone Hypersil BDS C18 column ( $2 \mathrm{~mm}$ x $300 \mathrm{~mm}, 3 \mu \mathrm{m})$. A gradient method was employed using $10 \%$ of $25 \mathrm{mM}$ ammonium hydroxide buffer $(\mathrm{pH}=3.5)$ and $90 \%$ water $(\mathrm{A})$, and $10 \%$ of buffer $\mathrm{pH}$ $=3.5$ and $90 \%$ acetonitrile (B), from 10 to $100 \%$ B in $2 \mathrm{~min}$ at $100 \%$ B from 2 to 5 minutes, from $10 \%$ to $5.2 \mathrm{~min}$.

\subsection{Preparation of standard solutions and calibration curves}

A stock solution of $100 \mu \mathrm{g} / \mathrm{mL}$ was prepared in methanol using the glibenclamide reference standard. Standards were prepared in the concentration range $0.1-100 \mu \mathrm{g} / \mathrm{mL}$. The peak area versus drug concentration was treated by linear least square regression analysis.

\subsection{Quality control}

The 7 test products and the innovator were tested for uniformity of content and assessment according to Mexican regulations [9]. Content uniformity is based on the assay of the drug substance in a number of individual dosage units to determine whether the individual contents are within set limits (Not less than $85 \%$ and not more than $115 \%$ ). The dosage form must not contain less than $90 \%$ and not more than $110 \%$ of the amount indicated on the label. 


\subsection{Dissolution}

Dissolution tests were performed in compliance with FEUM [10] using an apparatus 2 (paddles) at $75 \mathrm{rpm}$ and $500 \mathrm{~mL}$ of dissolution medium. The dissolution media employed was borate buffer $0.05 \mathrm{M} \mathrm{pH} \mathrm{9.5.} \mathrm{The} \mathrm{bath} \mathrm{temperature} \mathrm{was}$ maintained at $37 \pm 0.1^{\circ} \mathrm{C}$. Six drug products ( 6 tablets per manufacturer) were evaluated and dissolution samples were collected at $15,30,45$ and $60 \mathrm{~min}$. The medium was replaced at $37 \pm 0.5^{\circ} \mathrm{C}$ to a constant volume. At each time point, a $1 \mathrm{~mL}$ sample was removed from each vessel using a glass syringe and filtered through an acrodisc $囚$ filter $(0.45 \mu \mathrm{m}, 25$ $\mathrm{mm}$ ) into labeled glass tubes and transferred to amber vials for subsequent analysis. The amount of drug released from each tablet in the dissolution samples was determined by the HPLC method mentioned above. The analytical method used was previously validated (unpublished data).

Dissolution profiles for each product were compared with the innovator to determine the similarity of the generic products and innovator. The values of the response obtained were interpolated in a calibration curve prepared on the same day of the test. 12 dosage units per product were analyzed.

\subsection{Data analysis}

Analytical data were analyzed using Excel@ software programs for statistical and graphical comparisons. To compare the dissolution profiles of all generic and innovator brands, the model-independent approach of similarity factor $\left(f_{2}\right)$ must be employed. If the relative standard deviation (RSD) of the percentage dissolved of the reference drug is greater than that established (\%RSD dissolved is $\leq 20 \%$ for the first sampling time and $\leq 10 \%$ for subsequent times), an alternative statistical test should be used. For each product the percentage of drug dissolved with respect to nominal dose at the sampling times established was calculated according to the equation:

$\%$ Dissolved $=\{\mathrm{C}(\mathrm{mg} / \mathrm{mL}) *(100 \mathrm{~mL} /$ tablet weight $) *$ (average weight $/ 5 \mathrm{mg}) * 100\}$

\section{Results}

\subsection{Quality control of the products}

Five of 7 products under study met the Pharmacopoeia specifications for content uniformity (Table I). if one unit is outside the range of $85 \%$ to $115 \%$ of the amount declared on the label and no unit is outside the range of $75 \%$ to $125 \%$ of the declared amount, or if the RSD is more than $6 \%$, or if both conditions prevail, 20 additional units must be analyzed [9]. This was the case for product $\mathrm{C}$, which met the requirement that no more than 1 unit of the 30 units analyzed was outside the range from $85 \%$ to $115 \%$ of the amount declared in label, and no unit was outside the range of $75 \%$ to $125 \%$; nevertheless, the RSD of 30 units of dosage turned out to be more than $7.8 \%$ (7.9\%). Based on the requirements described in the Mexican regulations, product $\mathrm{C}$ is not considered interchangeable, due to that it did not comply with the content uniformity specifications, since it presented a content of $117.7 \%$ with a RSD of $8.6 \%$ (must contain between $85 \%$ and $115 \%$ of active principle with a RSD less than $7.8 \%$ ). Although all the analyzed products contained a percentage of active principle very close to the lower and upper limit of $90-110 \%$, the products B, D, F, G and $\mathrm{H}$, complied with the assay requirements. The product E presented a difference of assay requirement $5.36 \%$ greater than allowed compared with the innovator product (it must not be higher than $5 \%$ ).

Table 1 Quality control of pharmaceutical products

\begin{tabular}{llll}
\hline Product & $\begin{array}{l}\text { Uniformity of } \\
\text { content (\%)a }\end{array}$ & $\begin{array}{l}\text { Assay } \\
(\%))^{\mathbf{b}}\end{array}$ & $\begin{array}{l}\text { Average } \\
\text { weight(g) }\end{array}$ \\
\hline A (innovator) & $105.1(1.0)$ & $103.9(0.4)$ & $0.164(0.8)$ \\
B & $98.9(1.8)$ & $90.6(0.9)$ & $0.096(1.2)$ \\
C & $109.0(7.9)$ & $101.9(1.8)$ & $0.075(1.6)$ \\
D & $92.3(1.7)$ & $100.5(0.6)$ & $0.079(2.2)$ \\
E & $101.7(3.9)$ & $109.2(1.8)$ & $0.152(4.9)$ \\
F & $106.9(2.8)$ & $103.5(1.6)$ & $0.103(2.0)$ \\
G & $107.3(2.7)$ & $100.5(0.7)$ & $0.102(3.1)$ \\
H & $94.2(3.9)$ & $101.1(2.1)$ & $0.092(2.5)$ \\
\hline \multicolumn{4}{c}{${ }^{a}$ RSD Relative Standard Error } \\
\end{tabular}




\subsection{Dissolution test}

Table II shows the average of the percentage dissolved for each sampling time and the \%RD of the 12 units assessed for each product. It can be seen that only some products meet the requirement of the normativity [9], which establishes that the RSD $\%$ at the first sampling time must be $\leq 20 \%$ and $\leq 10 \%$ in the subsequent times, to proceed the calculation of the factor of similarity $f_{2}$. For this reason, the dissolution profile of the innovative drug was repeated twice in two different days. This trial also showed high \%RSD values. The Mexican normativity indicates that if the criteria mentioned above are not met, an alternative and sustainable statistical method that allows the comparison of the dissolution profiles must be applied. For this study, the analysis of variance proposed by Mauger et al. was used ( $p<0.05)[11]$.

The in vitro dissolution profiles of the tablets are shown in Figure 1. Each data point represents a mean of twelve measurements for each product. All products failed with the dissolution specification, $\mathrm{Q}$, as dissolution not less than $70 \%$ of the labeled amount of glibenclamide within $45 \mathrm{~min}$. The percentage of drug dissolved, calculated for the sampling times at 15, 30 and 45 min showed a high variability, it can be seen that the dissolution profiles of the test products do not show similarity with that of the innovator. This is consistent with what has been published by various authors who have found significant differences in terms of the amount of drug dissolved, particularity that presented those drugs with a low solubility and high permeability, as glibenclamide $[12,13]$.

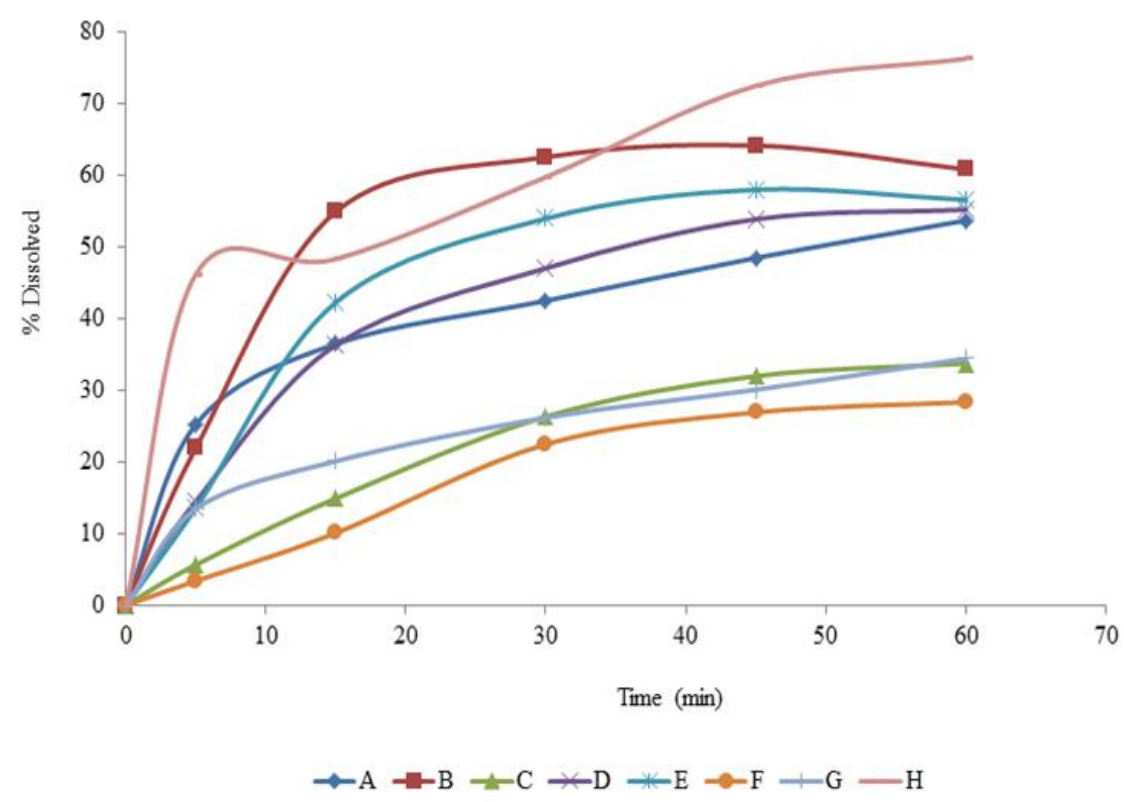

Figure 1 In vitro dissolution profiles of products acquired by Mexican Health Care System. Each data point represents a mean of twelve measurements.

According to the statistical method used, products D and E did not show statistically significant differences in dissolution profiles compared to the innovator product; nevertheless, the product E did not fulfill with the specification of the assay, thus only one product (product D) of the seven tested, can be considered interchangeable.

Five of seven generic products met the quality control specifications. One product did not meet the requirements established for the content uniformity test, and another one presented differences in assay limits being higher than that allowed in comparison with the innovator. It was possible to observe significant differences between the dissolution profiles at the different sampling times between the different laboratory products that supply the Mexican Health Sector. According to the alternative statistical method used, products D and F did not show statistically significant differences in dissolution profiles compared to the innovative product. Of the seven drugs evaluated, only one proved to be interchangeable. 
Table 2 Average of the percentage dissolved for each sampling time and the \%RSD of the 12 units assessed for each product

\begin{tabular}{|c|c|c|c|c|c|c|}
\hline Product & $\begin{array}{l}\text { Time } \\
\text { (minutes) }\end{array}$ & 5 & 15 & 30 & 45 & 60 \\
\hline \multirow[t]{2}{*}{ A (innovator) } & $\bar{x}$ & 25.2 & 18.2 & 21.2 & 24.2 & 26.8 \\
\hline & RSD (\%) & 19.3 & 14.9 & 13.3 & 11.6 & 8.7 \\
\hline \multirow[t]{2}{*}{ B } & $\bar{x}$ & 5.5 & 13.7 & 15.6 & 16.0 & 15.2 \\
\hline & RSD (\%) & 18.4 & 21.6 & 14.9 & 9.7 & 11.3 \\
\hline \multirow[t]{2}{*}{$\mathrm{C}$} & $\bar{x}$ & 14.9 & 16.7 & 19.7 & 22.8 & 23.4 \\
\hline & RSD (\%) & 11.9 & 12.0 & 8.7 & 7.9 & 8.7 \\
\hline \multirow[t]{2}{*}{$\mathrm{D}$} & $\bar{x}$ & 2.8 & 7.4 & 13.1 & 15.9 & 16.8 \\
\hline & RSD (\%) & 64.0 & 29.4 & 10.4 & 7.9 & 6.4 \\
\hline \multirow[t]{2}{*}{$\mathrm{E}$} & $\bar{x}$ & 7.2 & 18.1 & 23.5 & 26.9 & 27.6 \\
\hline & RSD (\%) & 40.7 & 15.6 & 12.4 & 10.8 & 9.9 \\
\hline \multirow[t]{2}{*}{$\mathrm{F}$} & $\bar{x}$ & 6.8 & 21.1 & 26.9 & 28.9 & 28.3 \\
\hline & RSD (\%) & 20.1 & 12.8 & 5.2 & 5.9 & 5.1 \\
\hline \multirow[t]{2}{*}{$G$} & $\bar{x}$ & 1.70 & 5.0 & 11.2 & 13.4 & 14.1 \\
\hline & RSD (\%) & 12.89 & 8.6 & 4.6 & 6.0 & 18.4 \\
\hline \multirow[t]{2}{*}{$\mathrm{H}$} & $\bar{x}$ & 4.9 & 16.8 & 31.1 & 31.6 & 30.4 \\
\hline & RSD (\%) & 28.0 & 31.6 & 3.9 & 3.9 & 4.7 \\
\hline \multirow[t]{2}{*}{ I } & $\bar{x}$ & 6.7 & 10.0 & 13.1 & 15.0 & 17.2 \\
\hline & RSD (\%) & 19.9 & 11.2 & 8.6 & 9.1 & 9.3 \\
\hline \multirow[t]{2}{*}{$\mathrm{J}$} & $\bar{x}$ & 23.1 & 24.1 & 29.8 & 36.2 & 38.1 \\
\hline & RSD (\%) & 14.3 & 11.8 & 11.6 & 25.2 & 7.0 \\
\hline
\end{tabular}

RSD Relative Standard Error

\section{Conclusion}

Five of seven generic products met the quality control specifications. One product did not meet the requirements established for the content uniformity test, and another one presented differences in assay limits being higher than that allowed in comparison with the innovator. It was possible to observe significant differences between the dissolution profiles at the different sampling times between the different laboratory products that supply the Mexican Health Sector. According to the alternative statistical method used, products D and F did not show statistically significant differences in dissolution profiles compared to the innovative product. Of the seven drugs evaluated, only one proved to be interchangeable. Properly controlled bio-equivalence studies are strongly recommended to further investigate the potential inequivalence of the tested products.

\section{Compliance with ethical standards}

\section{Acknowledgments}

Thanks to the MSc Raúl Morales for the facilities provided for the realization of the project.

\section{Disclosure of conflict of interest}

The authors declare that there is no conflict of interest. 


\section{References}

[1] Blume H, Ali SL and Siewert M. (1993). Pharmaceutical quality of glibenclamide products a multinational postmarket comparative study. Drug Development and Industrial Pharmacy, 19(20), 2713-2741.

[2] Coppack S, Lant A and Rodgers A. (1990). Pharmacokinetic and pharmacodynamics studies of glibenclamide in non-insulin dependent diabetes mellitus. British Journal of Clinical Pharmacology, 29(6), 673-684.

[3] Chalk JB, Patterson M, Smith MT and Eadie MJ. (1986). Correlations between in vitro dissolution, in vivo bioavailability and hypoglycaemic effect of oral glibenclamide. European Journal of Clinical Pharmacology, 31(2), 177-182.

[4] Kathri J, Qassim S, Abed O, Abram B, Al-Lami A and Massad SA. (2001). A novel extractionless HPLC Fluorescence method for the determination of glyburide in the human plasma: application to a bioequivalence study. Journal of Pharmacy \& Pharmaceutical Sciences, 4(2), 201-206.

[5] Idries AM, Ahmed ME, Mudawi ME and Ibrahim KE. (2012). Interchangeability and comparative effectiveness between micronized and non-micronized products of glibenclamide tablets. Sudan Journal of Medical Sciences, 7(3), 153-159.

[6] Marchetti P, Navalesi R. (1989). Pharmacokinetic-pharmacodynamic relationships of oral hypoglycaemic agents. An update. Clinical Pharmacokinetics, 16(2), 100-128.

[7] Boix A. Sustitución y selección de equivalentes terapéuticos. (1996). Farmacia Hospitalaria, 20(6), 351-358.

[8] García J, Salcedo A, Covarrubias V, Colunga C and Milke M. (2004). Diabetes mellitus tipo 2 y ejercicio físico. Resultados de una intervención. Revista Médica del IMSS, 40(5), 395-404.

[9] Norma Oficial Mexicana NOM-177-SSA1-2013, que establece las pruebas y procedimientos para demostrar que un medicamento es intercambiable. Diario Oficial de la Federación 20/09/2013.

[10] Farmacopea de los Estados Unidos Mexicanos. Comisión Permanente de Farmacopea de los Estados Unidos Mexicanos. 9a edición. Secretaria de Salud. México 2009. p.:309-10; 1040-1.

[11] Mauger J, Chilko D and Howard S. (1986). On the analysis of dissolution data. Drug Development and Industrial Pharmacy, 12(7), 969-992.

[12] Dressman J and Reppas C. (2000). In vitro -in vivo correlations for lipophilic, poorly water-soluble drugs. European Journal of Pharmaceutical Sciences, 11(S2), 573-580.

[13] Nokhodchi A, Javadzadeh Y, Isasi-Shadbad MR and Baezegar-Jalali M. (2005). The effect of type concentration of vehicles on the dissolution rate of a poorly soluble drug (indomethacin) from liquisolid compacts. Journal of Pharmaceutical Sciences, 8(1), 18-25.

\section{How to cite this article}

Sánchez-Nava LA, Bautista-Sánchez U and Robles-Piedras AL. (2019). Pharmaceutical equivalence and similarity studies of glibenclamide tablets. GSC Biological and Pharmaceutical Sciences, 7(1), 96-101. 